\title{
New psychoactive substances and the risks of consumption in children and adolescents
}

\author{
Viorela Nitescu
}

"Grigore Alexandrescu" Emergency Clinical Hospital for Children, Bucharest, Romania

\begin{abstract}
According to the definition established by the European Monitoring Center for Drugs and Drug Addiction (EMCDDA) a "new psychoactive substance is considered any narcotic or psychotropic substance in pure form or in preparations, which is not controlled by the Conventions regarding drugs of the United Nations and which represent a threat to human health comparable to that realized by the substances registered in these conventions considered illicit substances (1). There have been described 4 main classes of new psychoactive substances:synthetic cannabinoids (contained in plant mixtures), synthetic cathinones (contained in various bath salt powders),natural hallucinogens and piperazines (contained in tablets or capsules). Synthetic cannabinoids are synthetic agonists of cannabinoid receptors, constituting a group of synthetic substances that mimic the effects of $\Delta 9$ tetrahydrocannabinol (THC), the main product from cannabis, responsible for its psychoactive effects (4). Symptoms of poisoning are similar to those of cannabis poisoning but more severe, the clinical picture most commonly comprising: agitation, nausea, palpitations (9). Synthetic cathinones are compounds derived from cathinone - the main constituent of the Catha edulis plant known as KHAT (12). The effects of the consumption are similar to those of amphetamines, methamphetamines or cocaine. Natural hallucinogens are substances that in small doses have the main effect of altering the perception of thinking and mood with the preservation of lucidity along with minor effects on memory and orientation $(23,24)$. Despite the name, these substances rarely produce true hallucinations. The most popular natural hallucinogens are: salvinorin A, psilocybin and psilocyn muscimol and ibotenic acid. Piperazines are synthetic compounds similar to amphetamines but with weaker effects. The best known are: benzylpiperazines and phenylpiperazines (28).

Conclusions. The occasional consumption that can lead to acute intoxication or the chronic consumption of new psychoactive substances represents an important health problem occupying a place that should not be neglected in the pathology of adolescents and young people.
\end{abstract}

Keywords: new psychoactive substances, cannabinoids, cathinones, hallucinogens, piperazines

\section{INTRODUCTION}

According to the definition established by the European Monitoring Center for Drugs and Drug Addiction (EMCDDA) a "new psychoactive substance is considered any narcotic or psychotropic substance in pure form or in preparations, which is not controlled by the Conventions regarding drugs of the United Nations and which represent a threat to human health comparable to that realized by the substances registered in these conventions considered illicit substances (1).

They are contained in so-called "legal products" "legal highs" that are sold on the Internet, on the street or in some countries even in authorized shops, socalled "head and smart" shops. These "legal products" are mixtures of plants, powders, pills, bath salts, plant fertilizers, cleaning varnishes, etc., invariably being labeled currently not intended for human consumption $(2,3)$.
The consumption of these substances by adolescents and young people has become a so-called "spice" phenomenon, starting in the middle of 2000 , reaching a peak in the period 2008-2012, later registering a significant decrease but maintaining at a constant level of consumption as a result of legislative regulations throughout the European Union.

In our country the first cases of poisoning with new psychoactive substances were registered at the end of 2009, with the appearance in large numbers throughout the country of stores that sold these "legal products". The term initially used by both the general public and specialists for the name of these products was of "ethnobotanical", term later renounced, being replaced by "new psychoactive substances". The peak of consumption and consequently of intoxications with this type of substances was reached during 20102012, when their share in the consumption and intoxications with substances of abuse was the majority and 
the phenomenon had taken on a great extent constituting a very serious threat to health and lives of adolescents and young people. As a result of this fact in 2011 the Romanian authorities following the example of the majority of European countries have forbidden by law the commercialization and consumption of these types of products, the result being a significant decrease of both the consumption and the intoxications, that have stabilized at a constant level. This is relevant from the statistics performed in the National Pediatric Antitoxic Center of the Emergency Clinical Hospital for Children "Grigore Alexandrescu" Bucharest which showed that between 2010-2012 acute intoxications with new psychoactive substances represented $88.42 \%$ of the total acute intoxications with substances of abuse over time. Starting with 2013 their incidence decreased significantly, in the period $2013-2017$ representing only $12.6 \%$ of the total acute intoxications with substances of abuse.

\section{CLASSIFICATION}

There have been described 4 main classes of new psychoactive substances:

- synthetic cannabinoids (contained in plant mixtures)

- synthetic cathinones (contained in various bath salt powders)

- natural hallucinogens

- piperazines (contained in tablets or capsules)

\section{SYNTHETIC CANNABINOIDS}

Synthetic cannabinoids are synthetic agonists of cannabinoid receptors, constituting a group of synthetic substances that mimic the effects of $\Delta 9$ tetrahydrocannabinol (THC), the main product from cannabis, responsible for its psychoactive effects (4). These synthetic substances bind to cannabinoid receptors, achieving THC-like effects but with greater intensity and duration (5). It represents the largest group of new psychoactive substances monitored by the European Monitoring Center for Drugs and Drug Addiction through the early warning system: out of 731 substances new psychoactive drugs monitored by EMCDDA through the early warning system 190 were synthetic cannabinoids, with around 50 new substances being reported each year (6).

The main countries of origin are China and India (7) but in the last years several small artisan laboratories in Poland and Denmark have been discovered (6).

The chemical structure of synthetic cannabinoids consists of a side-chain, where optimal activity requires more than four up to nine satured carbon atoms (4), the common structure being $\Delta 9$ tetrahydrocannabinol.

There are described seven major structural groups of synthetic cannabinoids (4):

1. Naphtoylindoles - eg JWH018, JW073, JWH398

2. Naphthylmethylindoles

3. Naphthoylpyrroles

4. Naphthylmethyindenes

5. Phenylacetylindoles - eg. JWH-250

6. Cyclohexylphenols - eg CP47,497

7. Classical cannabinoids - HU-210.

The name of synthetic cannabinoids is related to either the mode of discovery or the chemical structure (2). For example the first synthetic cannabinoid: JW018 comes from the name of John W. Huffman, who described its chemical structure. In other cases the name comes from the names of the institutes where they were first synthesized: HU - Hebrew University, CP - Carl Pfeizer. In recent years, due to the increasing number of synthesized compounds the names have been allocated in relation to the chemical structure, for example: APICA - adamantyl-pentylindole carboxamide or APINACA - N-1-adamantyl1-pentyl-1-indazole 3 carboxamide.

The effects of using synthetic cannabinoids are as follows:

- relaxation, spontaneity, the perception of a slow passage of time, dizziness

- alteration of the sensor, difficulties in performing complex mental functions such as: learning, verbal communication or memory (8)

- increased appetite, dry mouth, conjunctival hyperemia, bright eyes

- tachycardia, sweating, decreased coordination of movements

Repeated consumption can lead to the phenomenon of addiction (addiction).

Symptoms of poisoning are similar to those of cannabis poisoning but more severe, the clinical picture most commonly comprising: agitation, nausea, palpitations (9).

Less common are: stroke, seizures, myocardial infarction, muscle fiber damage, kidney damage, incoercible vomiting, psychosis and even death $(10,11)$.

One of the most striking characteristics of the consumption of synthetic cannabinoids is the occurrence of mass poisonings: poisonings that occur in hundreds of people in a short period of time. For example, mass poisoning with MDMB FUBINACA described in Russia in 2014, and intoxication with ADB-FUBIN- 
ACA in the USA in 2015 or intoxication with the product called "Mocarz" in Poland in 2015.

\section{SYNTHETIC CATHINONES}

Synthetic cathinones are compounds derived from cathinone - the main constituent of the Catha edulis plant known as KHAT (12). From a chemical point of view they are $\beta$-keto $(\beta \mathrm{k})$ analogues of corresponding phenethylamine (12), having been identified so far 138 compounds $(6,13)$.

The most famous representatives of the group are:

- methcathinone - the first synthetic cathinone appeared on the illicit drug market

- mephedrone (4-methylcathinone) known by street name Miaow, M-Cat, is the most commonly used from synthetic cathinone group $(6,14)$

- methylone - it has the structure similar to MDMA (Ectasy) and is known by the street name Top-Cat (12)

- methedrone

- naphtylpyrovalerone -substance similar to pyrovalerone (2)

- numerous MDMA (Ectasy) substituents: MDAI, MMAI, MDMAT

Synthetic cathinones are in the form of white or brown powder, amorphous or crystalline powder, in different mixtures sold as: "plant fertilizer", "bath salt" or "chemical reagents" (15). They are rarely found in capsules or tablets and are sold as Ectasy.

The effects of the consumption depend on the type of the substance, being therefore similar to those of amphetamines, methamphetamines or cocaine. They can be consumed both in the form of capsules and snorted $(16,17)$. For example: mephfedrone is both snorted and consumed in capsules while methylone is predominantly consumed as capsules and rarely snorted because the powder is very irritating to the nasal mucosa (18).

Symptoms of intoxication are similar but more severe than those of amphetamine, methamphetamine or cocaine poisoning, depending on the type of substance $(2,12)$.

Thus, they were described:

- sympathomimetic effects similar to amphetamines and their derivatives $(19,20)$

- severe cardio-vascular effects: tachycardia, arrhythmias, circulatory disorders (21)

- neurological effects: seizures

- hyperthermia which is an effect typical of synthetic cathinones
The first synthetic cathinones have the same neurotoxicity with amphetamines and methamphetamines while newer compounds (MDAI, MDAT) are less neurotoxic compared to MDMA (Ectasy), which is why they are preferred by the consumers (22).

\section{NATURAL HALLUCINOGENS}

Hallucinogens are substances that in small doses have the main effect of altering the perception of thinking and mood with the preservation of lucidity along with minor effects on memory and orientation $(23,24)$. Despite the name these substances rarely produce true hallucinations.

Hallucinogens comprise three main classes: indolalkyl amines or tryptamines (ex. LSD, psilocin and psilocybin), fentanyl (mescaline and methylenedioxymethamphetamine - MDMA and cannabinoids.

The most popular natural hallucinogens are:

- salvinorin A

- psilocybin and psilocin

- muscimol and ibotenic acid

Salvinorin A is the most potent natural hallucinogen known to date, being active at very low doses of $200 \mu \mathrm{g}$. It has been identified in the Salvia divinorum plant, which is part of the mint family and is very similar but not identical to the plant used in nutrition Salvia officinalis (23). It is an agonist of the opioid receptor $\mathrm{k}$ and produces psychedelic hallucinogenic effects $(2,25)$.

Psilocybin ester phosphate is contained in hallucinogenic fungi: Psylocibe, Conocybe and Hygrocibe. In vivo it is hydrolyzed in psilocin needles having serotonin-like effects $(26,27)$.

Muscimol and ibotenic acid are compounds identified in the mushroom Amanita muscaria. They are analogues of $Y$-hydroxybutyric acid (GHB).

\section{PIPERAZINES}

Piperazines are synthetic compounds similar to amphetamines but with weaker effects.

There are two major described categories: benzylpiperazines and phenylpiperazines (28).

The best known benzylpiperazine is benzylpiperazine A2 having the street name Legal X, Pep X.

Phenyl piperazines constitute a more numerous group, the most important representative being 1,3 chlorfenilpiperazine-mCPP,1-3 trifluoromethiphenylpiperazine (TFMPP) and 1,4 methoxyphenylpiperazine (MeOPP).

Piperazines are found in the form of capsules or tablets. 
The effects of consumption are similar to those of MDMA (Ectasy) (29).

The symptoms of intoxication are the following:

- epigastric pain, nausea, tremor

- sleep disorders, confusion, irritability, grand mal status $(30,31)$

- serotonin syndrome, typical for mCPP: anxiety, migraine, panic attacks.

\section{OTHER NEW PSYCHOACTIVE SUBSTANCES}

Due to the numerous occurrence from year to year, many other substances or groups have appeared that do not belong to any of the group below/above (29).

These are the following:

- Synthetic derivatives of cocaine - dimetocaine and 4-fluorotropocaine - slight dopaminergic effects

- Ketamine and phencyclidine derivatives (Angel Dust)

- Natural and synthetic tryptamines - psilocin and bufotenin

- Mitragine - an alkaloid contained in the leaves of the Asian Mytragina tree known as Kratom or Biak-Biak

- Lisergamide - ergot-type alkaloid with chemical structure and action similar to LSD25 and found in the seeds of ,Morning Glory" plant (30)

\section{CLINICAL MANIFESTATIONS IN NEW PSYCHOACTIVE SUBSTANCES POISONING}

Symptoms of new psychoactive substances poisoning are varied and polymorphic (see table 1). The clinical picture includes both non-specific manifestations and specific manifestations depending on the type of substance or the mode of consumption (33).

Non-specific manifestations include: drowsiness, agitation, nausea.

Specific manifestations depending on the type of substance consumed are: agitation, nausea sometimes vomiting in the case of synthetic cannabinoids, cardio-vascular manifestations, especially tachycardia and arrhythmias in the case of synthetic cathinones, changes in perception and mood in hallucinogens, seizures or even convulsive mood in the case of piperazines but also of synthetic cathinones $(6,12)$.

In the case of consumption by inhalation the patient will present: cough, bronchoplegia, respiratory depression, in case of ingestion abdominal pain, vomiting, diarrhea, in case of injectable administration systemic effects sometimes installed quickly.
The onset of symptoms also depends on the mode of consumption. Thus: in case of inhalation or smoking they will start immediately after consumption, the maximum intensity being at 20-30 minutes and lasting 3-4 hours. In case of ingestion they start at 30-60 minutes up to 6 hours and in case of injection they can be installed almost immediately in the minutes following administration.

TABLE 1. The main clinical manifestations in new psychoactive substances poisoning

\begin{tabular}{|c|c|c|c|}
\hline No. & Category & $\begin{array}{l}\text { Presentation } \\
\text { forms }\end{array}$ & Poisoning manifestations \\
\hline 1. & $\begin{array}{l}\text { Synthetic } \\
\text { cannabinoids }\end{array}$ & Plant mixtures & $\begin{array}{l}\text { Similar to cannabis but } \\
\text { more severe } \\
\text { Agitation, psychosis } \\
\text { Palpitations, myocardial, } \\
\text { infarction } \\
\text { Nausea, incoercible } \\
\text { vomiting } \\
\text { Stroke, seizures, even death }\end{array}$ \\
\hline 2. & $\begin{array}{l}\text { Synthetic } \\
\text { cathinones }\end{array}$ & $\begin{array}{l}\text { White or } \\
\text { brown } \\
\text { powder } \\
\text { "Bath } \\
\text { salt","Plant } \\
\text { fertilizer" } \\
\text { "Chemical } \\
\text { reagents" }\end{array}$ & $\begin{array}{l}\text { Similar to amphetamine, } \\
\text { methamphetamine or } \\
\text { cocaine } \\
\text { Sympathomimetic effects } \\
\text { Severe cardio-vascular } \\
\text { effects: tachycardia, } \\
\text { arrhythmias, circulatory } \\
\text { disorders } \\
\text { Neurological effects: } \\
\text { seizures } \\
\text { Hyperthermia - typical } \\
\text { effect }\end{array}$ \\
\hline 3. & $\begin{array}{l}\text { Natural } \\
\text { hallucinogens }\end{array}$ & $\begin{array}{l}\text { Plants } \\
\text { (ex. Salvia } \\
\text { divinorum) } \\
\text { Mushrooms }\end{array}$ & Hallucinogenic effects \\
\hline 4. & Piperazines & $\begin{array}{l}\text { Tablets, } \\
\text { capsules }\end{array}$ & $\begin{array}{l}\text { Similar to MDMA (Ectasy). } \\
\text { Epigastric pain, nausea, } \\
\text { tremor } \\
\text { Confusion, tremor sleep } \\
\text { disorders } \\
\text { Irritability, grand mal status } \\
\text { Serotonin syndrome: } \\
\text { anxiety, migraine, panic } \\
\text { attacks }\end{array}$ \\
\hline
\end{tabular}

\section{TOXICOLOGICAL ANALYSIS}

There are no urine or blood screening tests to identify new psychoactive substances. However, they can give false positive reactions to urinary screening tests. For example, some synthetic cathinones may give false positive reactions to methamphetamine, given their similar structure $(2,34)$.

Some compounds can be identified only in highly specialized laboratories equipped with high performance equipment (35).

The identification of new psychoactive substances is very difficult to perform due to the great variety of 
the chemical structure but especially due to the rapid and continuous changes of their structure in the illicit laboratories, each year around 50 new structures are reported $(6,12)$.

\section{POSITIVE DIAGNOSIS}

Therefore, the positive diagnosis of new psychoactive substances acute poisoning will be established exclusively on the basis of medical history and clinical examination.

\section{TREATMENT}

Treatment is nonspecific and symptomatic including hydro-electrolytic and acid-basic rebalancing therapy, cardiac monitoring, sedation, etc.

\section{CHRONIC CONSUMPTION}

Chronic consumption of new psychoactive substances can cause severe disorders throughout the body. Cardiovascular disorders have been described: rhythm disorders, hypotension or hypertension, respiratory or digestive disorders. Particular attention should be paid to neurological and mental disorders that include: slowing down complex psychic mechanisms (learning ability, concentration and memory),

\section{REFERENCES}

1. New psychoactive substances (NPS) | www.emcdda.europa.eu. www. emcdda.europa.eu/topics/nps_en- acces septembrie-

2. Simon Gibbons. Legal Highs - novel and emerging psychoactive drugs: A chemical overview for the toxicologist. Clin Tox, 50(1), 15-24.

3. Sumnall HR, Evans-Brown M, McVeigh J. Social, policy, and public health perspectives on new psychoactive substances. Drug Test. 2011;3: 515-523.

4. Synthetic cannabinoids in Europe / www.emcdda.europa.eu. www. emcdda.europa.eu/topics/pods/synthetic-cannabinoids_en.

5. Cooper DZ. Adverse Effects of Synthetic Cannabinoids: Management of Acute Toxicity and Withdrawal. Curr Psychiatry Rep. 2016; 18(5): 52.

6. Highlighs from the EU Drug Market Report for policy and practice, EMCDDA, EUROPOL, Lisbon, November 2019.

7. US Department of Justice National Drug Intelligence Center Situation report: Synthetic cathinones (bath salts) - an emerging domestic threat 2011. Available from: http://www.justice.gov/archive/ndic/ pubs44/44571/44571p.pdf.

8. Tyndall JA, Gerona R, De Portu G et al. An outbreak of acute delirium from exposure to the synthetic cannabinoid AB-CHMINACA. Clin Toxicol. 2015; 53(10):950-956.

9. Phillips J, Lim F, Hsu R. Synthetic cannabinoid poisoning. A growing health concern. Nursing. 2019; 46(11):34-41.

10. Davis C, Boddington D. Teenage cardiac arrest following abuse of synthetic cannabis. Heart Lung Circ. 2015; 24:e162-e163.

11. Takematsu M, Hoffman RS, Nelson LS et al. A case of acute cerebral ischemia following inhalation of a synthetic cannabinoid. Clin Toxicol. 2014; 52:973-975. impairing mental lucidity and psychomotor coordination that are involved in complex activities such as driving the car $(36,37)$. Even psychiatric disorders such schizophrenia have been described in people who are predisposed (38).

Chronic consumption will lead in time to the phenomenon of tolerance (the need for exposure to increasing amounts of the substance to achieve the same effect initially obtained at lower doses) but also to the phenomenon of addiction, both psychic and physical $(39,40)$.

\section{CONCLUSIONS}

The occasional consumption that can lead to acute intoxication or the chronic consumption of new psychoactive substances represents an important health problem occupying a place that should not be neglected in the pathology of adolescents and young people.

Analyzing the characteristics of these substances from the way they are produced, the chemical structure and the speed with which they are introduced and changed, it can be said that the only way to prevent consumption is a permanent education sustained in schools and high schools.

Conflict of interest: none declared Financial support: none declared

12. EMCDDA | Synthetic cathinones profile (chemistry, effects). www. emcdda.europa.eu/publications/drug-profiles/synthetic-cathinones.

13. Riley AL, Nelson $\mathrm{KH}$ et al. Abuse potential and toxicity of the synthetic cathinones (i.e., "Bath salts"). Neurosci Biobehav Rev. 2019. pii: S0149-7634(18)30319-1.

14. European Drug Report 2019 -Trends and Developments, EMCDDA, Lisbon, Portugal, 2019: 56-62.

15. Spiller HA, Ryan ML, Weston RG et al. Clinical experience with and analytical confirmation of "bath salts" and "legal highs" (synthetic cathinones) in the United States. Clin Toxicol. 2011;49:499-505.

16. Dargan PI, Albert S, Wood DM. Mephedrone use and associated adverse effects in school and college/university students before the UK legislation change. QJM. 2010;103(11):875-879.

17. Centers for Disease Control and Prevention (CDC) Emergency department visits after use of a drug sold as "bath salts" MMWR Morb Mortal Wkly Rep. 2011;60(19):624-627.

18. Dargan P, Sedefov R, Gallegos A et al. The pharmacology and toxicology of the synthetic cathinone mephedrone (4-methylmethcathinone). Drug Test. Analysis. 2011: 454.

19. Sammler EM, Foley PL, Lauder GD, Wilson SJ, Goudie AR, O'Riordan JI. A harmless high? Lancet. 2010;376(9742):742.

20. Coppola M, Mondola R. Synthetic cathinones: Chemistry, pharmacology and toxicology of a new class of designer drugs of abuse marketed as "bath salts" or "plant food". Toxicol Lett. 2012; 211(2):144-149.

21. Hohmann N, Mikus G, Czock D. Effects and Risks Associated with Novel Psychoactive Substances. Mislabeling and Sale as Bath Salts, Spice, and Research Chemicals. Dtsch Arztebl Int. 2014; 111(9): 139-147. 
22. Prosser JM, Nelson LS. The toxicology of bath salts: A review of synthetic cathinones. J Med Toxicol. 2012;8(1):33-42.

23. EMCDDA - Hallucinogenic mushrooms profile (chemistry, effects...) www.emcdda.europa.eu/publications/drug-profiles/mushrooms.

24. Martins PB, Freeman S, Alder JF et al. Profiling psychoactive tryptamine-drug synthesis by focusing on detection using mass spectrometry. TrAC. 2010;29(4):285-296.

25. Williams RH, Erickson T. Evaluating Hallucinogenic orPsychedelic Drug Intoxicationin an Emergency Setting. Lab Med.2000; 31(7):394-401.

26. Gibbons S. 'Legal Highs' - Novel and emerging psychoactive drugs a chemical overview for the toxicologist. Clin. Toxicol. 2012;50(1):15-24.

27. Tittarelli R, Mannocchi G, Pantano F et al. Recreational Use, Analysis and Toxicity of Tryptamines. Curr Neuropharmacol. 2015; 13(1): 26.46.

28. EMCDDA - BZP/piperazines profile (chemistry, effects, other...) www. emcdda.europa.eu/publications/drug-profiles/bzp.

29. King LA, Kicman AT. A brief history of 'new psychoactive substances' Drug Test. Analysis.2011;3: 401-403.

30. Rosenbaum CD, Carreiro SP, Babu KM. Here Today, Gone Tomorrow... and Back Again? A Review of Herbal Marijuana Alternatives (K2, Spice), Synthetic Cathinones (Bath Salts), Kratom, Salvia divinorum, Methoxetamine, and Piperazines. J Med Toxicol. 2012; 8(1): 15-32.

31. Schep LJ, Slaughter RJ, Vale AJ, et al. The clinical toxicology of the designer "party pills" benzylpiperazine and trifluoromethylphenylpiperazine, Clin Tox. 2011;49(3):131-141
32. Juszczak GR, Swiergiel AH. Recreational Use of D-Lysergamide from the Seeds of Argyreia Nervosa, Ipomoea Tricolor, Ipomoea Violacea, and Ipomoea Purpurea in Poland. J Psychoactive Drugs. 2013; 45(1):79-93.

33. Elliott S, Evans J. A 3-year review of new psychoactive substances in casework. Forensic Science International.2014;243:55-60.

34. Elliott S. Cat and mouse: The analytical toxicology of designer drugs. Bioanalysis 2011;3: 249-251.

35. Dignam G, Bigham C. Novel psychoactive substances: A practical approach to dealing with toxicity from legal highs. BJA Education. 2017; 17(5): 172-177.

36. Graziano S, Orsolini L, Concetta Rotolo M et al. Herbal Highs: Review on Psychoactive Effects and Neuropharmacology. Current Neuropharmacology. 2017;15: 750-761.

37. Darke S, Kaye S, Ketin RMC et al. Major physical and psychological harms of methamphetamine use. Drug Alcohol Rev 2008; 27: 253-62.

38. Miliano C, Serpelloni G, Rimondo C et al. Neuropharmacology of New Psychoactive Substances (NPS): Focus on the Rewarding and Reinforcing Properties of Cannabimimetics and Amphetamine-Like Stimulants. Front Neurosci. 2016; 10(153):1-21.

39. Lopes GM, Araujo Nobrega B, Del Prette G et al. Use of psychoactive substances by adolescents:current panorama. Brazilian $J$ Psychiatry 2013; 35:S51-S61.

40. Scherbaum N, Schifano F, Bonnet U. New Psychoactive Substances (NPS) - a Challenge for the Addiction Treatment Services. Pharmacopsychiatry. 2017.50(3):116-122. 